\title{
Characterising the loading direction sensitivity of 3D woven composites: Effect of z-binder architecture
}

DOI:

10.1016/j.compositesa.2016.08.028

\section{Document Version}

Accepted author manuscript

Link to publication record in Manchester Research Explorer

\section{Citation for published version (APA):}

Saleh, M., Yudhanto, A., Potluri, P., Lubineau, G., \& Soutis, C. (2016). Characterising the loading direction sensitivity of 3D woven composites: Effect of Z-binder architecture. Composites Part A: Applied Science and Manufacturing, 90, 577-588. https://doi.org/10.1016/j.compositesa.2016.08.028

\section{Published in:}

Composites Part A: Applied Science and Manufacturing

\section{Citing this paper}

Please note that where the full-text provided on Manchester Research Explorer is the Author Accepted Manuscript or Proof version this may differ from the final Published version. If citing, it is advised that you check and use the publisher's definitive version.

\section{General rights}

Copyright and moral rights for the publications made accessible in the Research Explorer are retained by the authors and/or other copyright owners and it is a condition of accessing publications that users recognise and abide by the legal requirements associated with these rights.

\section{Takedown policy}

If you believe that this document breaches copyright please refer to the University of Manchester's Takedown Procedures [http://man.ac.uk/04Y6Bo] or contact uml.scholarlycommunications@manchester.ac.uk providing relevant details, so we can investigate your claim.

\section{OPEN ACCESS}




\section{Accepted Manuscript}

Characterising the loading direction sensitivity of 3D woven composites: Effect of z-binder architecture

Mohamed Nasr Saleh, Arief Yudhanto, Prasad Potluri, Gilles Lubineau, Constantinos Soutis

PII: S1359-835X(16)30284-6

DOI: http://dx.doi.org/10.1016/j.compositesa.2016.08.028

Reference: JCOMA 4404

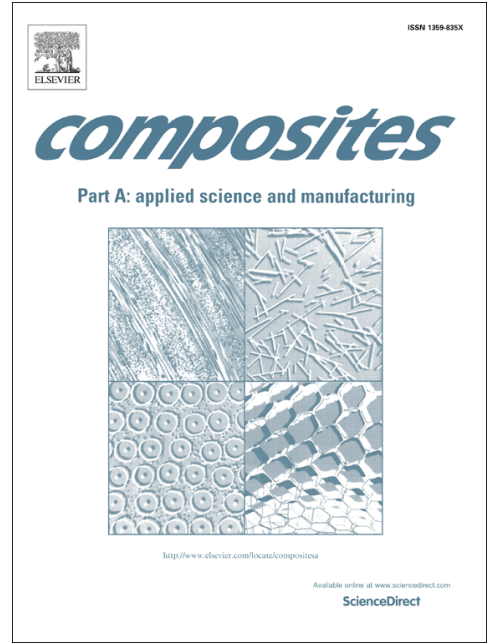

To appear in:

Composites: Part A

Received Date:

24 December 2015

Revised Date:

28 May 2016

Accepted Date:

23 August 2016

Please cite this article as: Saleh, M.N., Yudhanto, A., Potluri, P., Lubineau, G., Soutis, C., Characterising the loading direction sensitivity of 3D woven composites: Effect of z-binder architecture, Composites: Part A (2016), doi: http:// dx.doi.org/10.1016/j.compositesa.2016.08.028

This is a PDF file of an unedited manuscript that has been accepted for publication. As a service to our customers we are providing this early version of the manuscript. The manuscript will undergo copyediting, typesetting, and review of the resulting proof before it is published in its final form. Please note that during the production process errors may be discovered which could affect the content, and all legal disclaimers that apply to the journal pertain. 


\title{
Characterising the loading direction sensitivity of 3D woven composites: effect of $\mathrm{z}$-binder architecture
}

\author{
Mohamed Nasr Saleh ${ }^{1}$, Arief Yudhanto ${ }^{2}$, Prasad Potluri ${ }^{1}$, Gilles Lubineau ${ }^{2}$, Constantinos \\ Soutis $^{3}$ \\ ${ }^{1}$ School of Materials, University of Manchester, Manchester, M13 9PL, UK \\ ${ }^{2}$ King Abdullah University of Science and Technology (KAUST), Physical \\ Sciences and Engineering Division, COHMAS Laboratory, Thuwal 23955-6900, \\ Saudi Arabia \\ ${ }^{3}$ Aerospace Research Institute, University of Manchester, M1 3NJ, UK.
}

\begin{abstract}
Three different architectures of 3D carbon fibre woven composites (orthogonal, ORT; layer-to-layer, LTL; angle interlock, AI) were tested in quasi-static uniaxial tension. Mechanical tests (tensile in on-axis of warp and weft directions as well as $45^{\circ}$ off-axis) were carried out with the aim to study the loading direction sensitivity of these 3D woven composites. The z-binder architecture (the through-thickness reinforcement) has an effect on void content, directional fibre volume fraction, mechanical properties (on-axis and offaxis), failure mechanisms, energy absorption and fibre rotation angle in off-axis tested specimens. Out of all the examined architectures, 3D orthogonal woven composites (ORT) demonstrated a superior behaviour, especially when they were tested in $45^{\circ}$ off-axis direction, indicated by high strain to failure $(\sim 23 \%)$ and high translaminar energy absorption $\left(\sim 40 \mathrm{MJ} / \mathrm{m}^{3}\right)$. The z-binder yarns in ORT architecture suppress the localised damage and allow larger fibre rotation during the fibre "scissoring motion" that enables further strain to be sustained by the in-plane fabric layers during off-axis loading.
\end{abstract}

Keywords: A. Carbon fibre, A. 3-Dimensional reinforcement, C. Damage mechanics, $D$. Mechanical testing 


\section{Introduction}

Two-dimensional (2D) laminated composites, offering high in-plane stiffness and strength, have been widely used to build structures in automotive and aerospace industries. However, 2D composites are generally weak in the thickness direction (z-axis). Some applications of composites, nonetheless, require excellent out-of-plane properties for delamination resistance and impact damage resistance, e.g., wind turbine blades, airframe stringers and stiffeners and pressure vessels. Three-dimensional (3D) composites are thus an excellent choice for such applications. One class of 3D composites that receives a great attention is 3D woven composites whereby longitudinal yarns ("warp" or $0^{\circ}$ fibre tows), transverse yarns ("weft" or $90^{\circ}$ fibre tows) and through-thickness yarns (z-binder) are interlaced with a specific weaving architecture. 3D woven composite architectures can be grouped (according to the angle between the binding yarns and the in-plane yarns "warp/weft") into two main groups. When the interlacement angle is $90^{\circ}$, the $3 \mathrm{D}$ woven composite is called Orthogonal; other than that, it is referred to as Angle Interlock. Then, these two main groups can be further subdivided into layer to layer (binder goes between layers) or through-thickness (binder goes through the entire thickness). This interlacing process to produce $3 \mathrm{D}$ woven fabric can be done at faster rates since the existing textile technology can be adopted. As such, design flexibility to produce various weaving architecture is achieved, and near-net-shape preforms can be attained [1]. The delamination resistance [1] and impact performance [2-6] of 3D woven composites have been found to be outstanding thanks to the effectiveness of through-thickness reinforcement yarn ( $\mathrm{z}$ binder) in resisting "preventing" the growth of damage (delamination between plies).

Although the potential use of 3D woven composites is clearly apparent, their application is still limited [7] for various reasons. The first reason is that 3D woven composites generally exhibit lower in-plane properties in comparison with 2D non-crimp fabric (NCF) laminated composites [8,9] since they are inherently characterised by undulation or "crimp". This crimp is a direct result of the interlacement of longitudinal, transverse and through-thickness yarns [10]. The degree of crimp is dependent on the adopted woven architectures and the tension force during the weaving process. Secondly, the damage mechanisms in 3D woven composites are complex as they involve interaction 
among damage modes within and between yarns, effect of rich resin regions, voids and geometrical imperfections due to the manufacturing and compaction process. Thirdly, 3D woven composites are loading sensitive as yarns are distributed in three directions. For instance, the response of 3D woven composites in warp and weft directions can be different. The problem is more complex when off-axis (bias) loading is considered. Nevertheless, complex shape of composite structures, e.g., turbine blade structure, may be subjected to various degree of off-axis loading even when the structure itself is uniaxially loaded. In light of potential use of 3D woven composites for such impact-prone structures, it is thus important to understand the behaviour of various types of 3D woven composites under different loading directions. One of the assessments is through simple tensile tests on various 3D woven architectures under on-axis (warp- and weft-directions) and off-axis loadings (bias direction). Such assessment is also essential to evaluate the efficacy of "energy-based" design where the energy absorbed by 3D woven composite is considered. As such, the underlying mechanism behind the absorbed energy in various types of 3D woven composites under in-plane loading directions can be understood.

Much work has been done to characterise the failure mechanisms of 3D woven composites under tension [6,11-22] along the warp- or weft-directions. Gerlach et al. [6] who investigated angle interlock 3D woven composites subjected to tension (warp, weft) showed that the effect of z-binder volume fraction on the in-plane properties is minor. Cox et al. $[14,15]$ studied the failure mechanism of 3D woven composites (orthogonal, layer-tolayer) monotonically loaded in tension, compression and bending. They found that the dominant failure modes in 3D interlock woven composites are tow rupture and pull-out (tension case), delamination and kink-band formation (compression case), combination of those failure modes (bending case). Influence of fabric architecture in 3D woven composite under tensile, compressive and bending loads was investigated by Dai et al. [11] where they found that the mechanical performance is affected by resin rich region and waviness of load-carrying fibres. They also showed that angle interlock outperforms orthogonal 3D woven composite for all loading conditions. For 3D orthogonal woven composites under tension, Lomov et al. [16] found that damage initiates firstly at binder interlacement points. It is then followed by transverse cracks in yarns perpendicular to the loading direction and 
local delamination between yarns. Final failure is characterised by fibre failure that leads to complete rupture of specimen. Warren, et al. [21] characterised the global stress-strain curves and failure modes of 3D twill harness orthogonal woven composite, 3D layer-tolayer woven composite and 2D woven architecture under warp and weft tensions. In-plane shear test was also carried out using V-notched rail shear method, where they found that the shear among adjacent tows and matrix degradation are the dominant damage mechanisms in shear. Visrolia and Meo [22] performed on-axis tension ( $0^{\circ}$ direction), off-axis tension ( $45^{\circ}$ direction) and compression tests to validate their modelling strategy for 3D orthogonal woven composite. A good agreement of global stress-strain was demonstrated between their proposed model and the experimental results, although for off-axis tension the experimental results were reported up to $3 \%$ strain only (not until failure) and the damage mechanism under shear was not revealed. Pochiraju and Chou [19] reported the behaviour of 3D woven composites (layer-to-layer angle interlock, through-thickness angle interlock) under tension in warp and weft directions. Nonetheless, limited work has been performed to characterise 3D woven composites under off-axis loading (bias direction). Off-axis loading studies have been reported for non-crimp fabric (NCF) composites [23]. Ivanov et al. [24] have reported loading direction sensitivity (warp, weft, bias) of 3D woven composites but the materials were limited to orthogonal architecture. Nevertheless, there is still a need to evaluate the loading sensitivity of various architectures of 3D woven composites subjected to warp, weft and bias loadings. The relationship between damage mechanisms and energy absorption also needs to be revealed.

This research work aims to extend the characterisation of 3D woven composites with the main focus on the off-axis tensile loading (bias $45^{\circ}$ ). Three types of 3D woven architecture are considered here: (i) layer-to-layer (LTL), (ii) angle interlock (AI), and (iii) orthogonal (ORT). The materials were loaded, in tension, in warp, weft and bias $\left(45^{\circ}\right)$ directions where global stress-strain curves, failure mechanisms and energy absorption were assessed. This paper is divided into five sections. Section 2 describes the architecture of 3D woven composites used in present experiments, and their manufacturing details. Section 3 describes the material characterisation (fibre volume fraction measurement) and mechanical tests (tensile tests coupled with digital image correlation analysis). Section 4 
presents the results and discusses the experimental findings (effect of $\mathrm{z}$-binder on directional volume fraction, stress-strain responses, failure mechanism and energy absorption). Finally, section 5 highlights the concluding remarks of the paper.

\section{Materials and manufacturing}

The carbon fibre, used in this study, is HexTow IM7 (Hexcel), while the epoxy is MTM 57 (medium temperature epoxy produced by Cytec). The 3D woven dry fabrics are produced by Sigmatex UK. Three architectures are investigated, namely orthogonal (ORT), layer-to-layer (LTL) and angle interlock (AI). Fig. 1 shows the schematic architecture of three 3D woven fabrics drawn using TexGen software. Specification of the textile architecture parameters of 3D woven composites are detailed in Table 1. Warp and weft fibre count for ORT, AI and LTL is $12 \mathrm{k}$. The z-binder fibre count for ORT, AI and LTL is $6 \mathrm{k}, 6 \mathrm{k}$ and $12 \mathrm{k}$, respectively. The number of warp threads, weft threads and $\mathrm{z}$-binder threads per unit length (centimetre) is specified in Table 1 as ends/cm, picks/cm and binders/cm, respectively. In addition, the areal density of the dry 3D woven fabric is also given in Table 1 (unit is $\mathrm{g} / \mathrm{m}^{2}$ ).

To produce 3D woven composite panels, the dry fabrics were infiltrated by MTM 57 epoxy matrix using resin film infusion (RFI) process. Infusion process was carried out at $70^{\circ} \mathrm{C}$ for $1 \mathrm{~h}$, while curing process was done at $120^{\circ} \mathrm{C}$ for $1 \mathrm{~h}$. Minimum curing pressure for MTM 57 was set to 2.8 bars. Once the 3D woven composite panels with the size of 300 mm x $200 \mathrm{~mm}$ were cured, they were cut into three different orientations (see Fig. 2). Thickness of cured composite panels ranges between 3.2 to $3.6 \mathrm{~mm}$ depending on the warp and weft number of layers.

\section{Experimental procedures}

\subsection{X-ray computed tomography}

In order to evaluate the deviation, of the "as-manufactured" 3D woven composite panels, from the idealised geometry and compare afterwards with the damaged specimens, X-ray CT scans were performed on the three architectures (ORT, LTL and AI) using a Zeiss Xradia VersaXRM-510 machine. To obtain a sufficient resolution, a square cross 
section of (30 mm x $30 \mathrm{~mm})$ was cut from the sample. The $0.4 \times$ objective of the scanner was used. For ORT sample, the total volume in the field of view was $10 \times 10 \times 10 \mathrm{~mm}^{3}$, resulting in a voxel size of $5 \mu \mathrm{m}$. The source voltage and current were set to $40 \mathrm{kV}$ and 75 $\mu \mathrm{A}$ respectively. The exposure time for each radiograph was $10 \mathrm{~s}$, with 1600 radiographs being collected over 360o. The total data acquisition time was 7 hours. Similarly, all scanning parameters were kept the same for LTL and AI except for the total volume in the field of view and consequently the voxel size. As both LTL and AI have larger unit cells, the field of view was increased to $16 \times 16 \times 16 \mathrm{~mm}^{3}$ and $25 \times 25 \times 25 \mathrm{~mm}^{3}$ respectively.

After scanning, the 3D unit cells (Fig. 3a, c, e) were reconstructed out of the 2D Xray slices for ORT, LTL and AI. Using a cutting plane parallel to the warp yarns, X-CT section view (Fig. 3b, d, f) clearly shows voids and binder distortion, due to weaving process, RFI process and fabric compaction for all the architectures that can have impact on stiffness, damage initiation and ultimate specimen failure. In addition, in the case of LTL architecture (Fig. 3d), the weft layers are distorted in the vertical plane and resin rich regions are shown in black. Unlike ORT and LTL architectures, the AI architecture cross section (Fig. 3f) suggests that it has the most severe binder distortion.

\subsection{Determination of fibre volume fraction}

In this study, the determination of fibre volume fraction of the manufactured panels was conducted in two stages. The first stage deals with an experimental measurement of fibre volume fraction $V_{f}$ (as well as matrix $V_{m}$ and void volume fraction $V_{v}$ ) of samples from the manufactured panels. The second stage deals with an analytical calculation to determine directional $V_{f}$ in warp, weft and z-directions based on textile parameters given in Table 1 . The procedures of both stages are described in the following sections.

\subsubsection{Acid digestion}

Fibre volume fraction measurement was conducted based on acid digestion technique according to ASTM D3171 standard (Constituent Content of Composite Materials). The procedure is generally described as follows: (i) specimen is immersed in the sulfuric acid where the matrix is entirely dissolved; (ii) weight of the specimen is measured before and after the digestion process. The measurement of fibre volume fraction by acid digestion also enables the measurement of the matrix volume fraction as well as void 
content. Readers are referred to the ASTM D3171 document for more detailed experimental and specimen requirements.

\subsubsection{Directional fibre volume fraction analysis}

Directional fibre volume fraction analysis aims to calculate fibre volume fraction in warp, weft and z-directions, and to eventually determine the contribution of each directional fibre tows on the overall $V_{f}$. The calculation of directional $V_{f}$ can be summarised as follows: first, directional areal density of the fabric in warp, weft and z-binder direction is calculated by multiplying the yarns' count (in tex) by ends $/ \mathrm{cm}$, picks $/ \mathrm{cm}$ and binders $/ \mathrm{cm}$, respectively. Second, the directional areal density is then normalised by the total areal density to determine the percentage of warp, weft and z-binder fibres (directional $V_{f}$ ).

\subsection{Tensile testing}

Tensile test was carried out on on-axis (warp, weft) and $45^{\circ}$ off-axis specimens of LTL, AI and ORT. Instron 5882 with $100 \mathrm{kN}$ load cell was used to apply a displacementcontrolled tension with loading speed of $2 \mathrm{~mm} / \mathrm{min}$ according to ASTM D3039 standard (Tensile Properties of Polymer Matrix Composite Materials). Four specimens were tested for each type (LTL, AI, and ORT) and each orientation $\left(0^{\circ}, 90^{\circ}\right.$ and $\left.45^{\circ}\right)$. Specimens' dimensions were in accordance with ASTM D3039 standard, i.e. $250 \mathrm{~mm}$ long and $25 \mathrm{~mm}$ wide with a gauge length of $150 \mathrm{~mm}$. All tests were performed in a controlled environment where the temperature was $21{ }^{\circ} \mathrm{C}$ and the relative humidity $(\mathrm{RH})$ was $45 \%$. The tensile test setup shown in Fig. 4a consists of two main data acquisition channels for load and displacement within Instron 5882. Strains were acquired using digital image correlation (DIC) system utilising SensiCam 12-bit CCD camera (PCO) with TC-2336 bi-telecentric lenses (The Telecentric Company) shown in Fig. 4a. The resolution of CCD camera was $1376 \times 1040$ pixels. The bi-telecentric lenses has a depth of field of $11 \mathrm{~mm}$, diameter of 61 $\mathrm{mm}$ and magnification of $0.234 \mathrm{x}$. Fig. $4 \mathrm{~b}$ shows a typical speckle pattern on a specimen's surface. CamWare V3.11 software was used to capture the speckle pattern images acquired from the CCD camera. Similar setting has been successfully used for 3D stitched composites, and proven to provide reasonable quality of strain fields for $3 \mathrm{D}$ composites [25]. The frame rate is set as 0.5 and 0.33 frames per second (fps) for on-axis and off-axis tensile testing, respectively. The main reason for the lower fps in off-axis tests is that the 
deformation up to failure in off-axis specimens is much larger than that in on-axis tests. The speckle images were then processed using Vic 2D. In processing these images, the subset size was set to the maximum value of 101 x 101 pixels adequate for woven specimens. In addition, the step size (distance between subsets) was set to 5 pixels. The observation window of approximately $25 \times 22 \mathrm{~mm}^{2}$ produced an image with dimensions of 1040x896 pixels. Global mean values of strains $\left(\varepsilon_{x x} ; \varepsilon_{y y} ; \varepsilon_{x y}\right)$ are obtained from DIC analysis using Vic 2D.

\section{Results and discussion}

\subsection{Effect of z-binder on directional $V_{f}$}

Table 2 shows the fibre, matrix and void volume fractions of 3D woven composites. LTL exhibits higher $V_{f}$ of $59.16 \%$ in comparison to other materials due to its higher amount of z-binder $(12 \mathrm{k})$. However, it is noteworthy that z-binders generally introduces higher amount of void in $3 \mathrm{D}$ woven composites in comparison to $2 \mathrm{D}$ composites $[7,8]$. The architecture of z-binder reduces the amount of resin that is flowing into areas between warp and weft tows. This is also aggravated by the fact that RFI process does not employ a transportation medium for resin to flow. In other words, Table 2 suggests that weaving architecture affects the void content "porosity" of the infused panel. AI architecture has a smoother weaving pattern as compared to ORT, while the LTL architecture has the smoothest weaving pattern among all 3D woven investigated architectures. Smoother weaving pattern improves the resin flow between fabric layers and resin infiltration into the fabrics. As such, smoother weaving pattern would have lower void content. This explains the lower void content in the LTL materials. As also observed, the void content in AI is greater than the LTL, but less than that in ORT, which has the most complex weaving pattern and consequently the highest void content. The total fibre volume fraction given in Table 2 is then divided into warp, weft and z-binder content, and Table 3 shows the socalled directional $V_{f}$.

\subsection{Effect of z-binder on on-axis mechanical properties}

The stress-strain curves for ORT, LTL and AI tested up to failure are shown in Fig. 5a-c, respectively. The stress-strain curves, either in warp or weft direction, demonstrate 
good repeatability. The curves for ORT and LTL shown in Figs. 5a and b indicate that the specimens tested in weft direction are stiffer and stronger that those tested in warp direction. This is primarily due to the fact that ORT and LTL specimens have higher directional $V_{f}$ in weft direction than that in warp direction (see Table 3). When directional $V_{f}$ is similar between weft and warp directions, as in the case of AI specimens, the tensile stress-strain curves exhibit similar trend (Fig. 5c). Based on the stress-strain curves shown in Figs. 5a-c, the mechanical properties (Young's modulus, tensile strength and failure strain) of 3D woven composites are given in Table 4.

The strain contour $\left(\varepsilon_{y y}\right)$ obtained by the DIC system from the surface of ORT, LTL and AI specimens captured at ultimate stress is plotted in Figs. 6a-c. A spectrum of colour map on the right side of each DIC image corresponds to the strain values. The region with high strain values is indicated with red colour, and this region is the interlacement points between z-binders and weft yarns. In addition, the strain contour obtained by DIC was also used to identify the unit cell of $3 \mathrm{D}$ woven composites based on the periodicity of the weaving pattern. Here, the dimension of the unit cell of ORT, LTL and AI specimens are identified to be approximately $5 \times 5 \mathrm{~mm}^{2}, 10 \times 7 \mathrm{~mm}^{2}$ and $20 \times 25 \mathrm{~mm}^{2}$, respectively. The periodicity of the strain contours could be useful for validating the models of 3D woven composites utilising, for instance, asymptotic expansion homogenisation method reported in [22,26-28] and the full-field measurement-based identification models [29].

\subsection{Effect of z-binder on off-axis mechanical properties}

Stress-strain curves of 3D composites loaded in bias direction of $45^{\circ}$ are shown in Fig. 7 where they show bilinear response. The "knee point" is defined as the transition point from the first to the second linear curve; and similar to angle ply laminate case reported in [30] this second linear curve is associated with matrix cracking and inter-yarn matrix delamination that leads to gradual change of stiffness. As shown in Fig. 8, the failure strain of ORT, LTL and AI is $24.20 \%, 11.27 \%$ and $13.29 \%$ respectively. The z-binders affect the rotation of biased fibre tows, and eventually the strain hardening and failure onset of 3D woven composites. Table 5 summarises the tensile modulus, strength and failure strain which are derived from the off-axis stress-strain curves. Both AI and ORT demonstrate higher strength and strain to failure compared to LTL which suggests that 
through-thickness binder improves the performance of off-axis loaded 3D woven composites compared to the layer-to-layer binder. Moreover, the effect of the z-binder yarns architecture is obvious when ORT is compared against AI. The following sections investigate in detail the effect of the z-binder architecture on the off-axis 3D woven composites' strength, damage mechanisms and energy absorption.

\section{Remarks:}

1- For LTL and AI a necking region is developed that leads to final fracture. Before localisation, the measured strain is considered as a good estimation of the developed strain. However If localisation occurs outside the ROI of the DIC, the strain measured might not be accurate. The dashed line on Fig. 7 indicates the value after which the strain measurement might not be valid.

2- Approaching the point of failure in off-axis samples, several fibre bundles ruptured from the specimen surface within the DIC region, which caused some of the speckle pattern to debond. This might have an effect on determining the ultimate failure strain which is reported in Table 5. In this study, for the determination of failure strain, it was decided to select the point at which the strain value has not yet being disturbed. Unfortunately, conventional strain gauges bonded on the specimen or non-contact strain gauges would suffer from the same problem.

\subsection{Effect of z-binder on failure mechanism}

Macroscopic failure of 3D woven composites tested on-axis is shown in Fig. 8. The failure is characterised by a clear transverse fracture (perpendicular to the loading direction) across the whole width of the specimens. This indicates that the final fracture is predominantly due to longitudinal fibre breakage. In terms of failure mechanisms, damage initiation and progression up to final failure in on-axis 3D woven composites has been reported in $[16,28,31,32]$. The damage initiation and progression were found to be similar for orthogonal, layer-to-layer and angle interlock architectures. The damage typically starts at the interlacement points between z-binder and warp (or weft) yarns where the local stress fields are amplified. Following the stress localisation at the interlacement points, transverse cracks within the yarns, perpendicular to the loading direction, grow instantaneously and multiply in number up to a saturation point. Then, the damage mechanism changes from 
transverse cracking to delamination (between warp and weft yarns and along the z-binder boundary), and this transition happens at the last stages of loading prior to fibre tow breakage.

Since the study of damage initiation and progression in off-axis 3D woven composite is very limited, here an interrupted test (at several load levels) was performed on the three architectures, and the underlying damage mechanisms were observed by X-ray machine (X-Tex XTH 225 cone-beam tomograph). The scanning spatial resolution was approximately $16 \mu \mathrm{m}$; and a diodomethane dye-penetrant from (Sigma Aldrich) was applied on the surface of specimens for one hour prior to scanning. Three stress levels (Points B, C, D) from the off-axis stress-strain curve of 3D woven composites were selected (see Fig. 9). The region of interest (ROI) for this observation is the centre of the specimen. Point A denotes zero stress where non-damage specimen was captured by X-ray as a reference. The strain level of the "knee point" in the off-axis tensile curves (and the corresponding tensile stress) of ORT, LTL and AI are given in Table 6. Point B was selected at the linear elastic segment (approximately $60 \mathrm{MPa}$ ) in order to characterise the damage initiation before the "knee point". Point C was around $110 \mathrm{MPa}$, which is a point after the knee point where damage progression was investigated. Point D was selected just before the specimen failure (around 95\% of UTS), where the damage prior to failure was studied. The stress level for Point D was actually different for three architectures due to different UTS: the stress level is $210 \mathrm{MPa}, 120 \mathrm{MPa}$ and $170 \mathrm{MPa}$ for ORT, LTL and AI specimens, respectively. X-ray images were captured with X-ray setting of $35 \mathrm{kV}$ and 310 $\mu \mathrm{A}$. To aid the damage analysis using X-ray, nomenclature of damage types is given in Table 7 .

At Point A, no damage due to manufacturing is observed by X-ray. After the specimen was loaded to $60 \mathrm{MPa}$, the first damage characteristic at Point B observed in all architectures is free-edge matrix cracking (F-type). Damage at Point B is caused by the interlaminar stresses between layers as reported in [33-35]. Increasing the applied stress, Ftype cracks propagate towards the centre of the specimens. Reaching Point $\mathrm{C}$, three damage types are identified. ORT and AI specimens exhibited binder-induced damage (Z-type) at the interlacement points between the in-plane yarns and the binding yarns. Transverse 
cracking (T-type) within yarns starts to multiply in number associated with inter-yarn matrix delamination (D-type). The (D-type) damage is driven by the in-plane yarns realignment and rotation towards the loading axis (see Section 4.5). In case of LTL specimen, accumulation of the (D-type) cracks is more severe as it has the least strength ( 130 MPa) while no Z-type damage can be observed. Up to this stress level, there is no significant difference in the damage mechanisms between the three architectures. At Point D ( $95 \%$ UTS), the damage accumulation and evolution changed dramatically. In ORT specimen, D-type cracks are arrested by the z-binder yarns while (T-type) cracks multiple in number. In ORT specimen, damage is uniformly distributed over the ROI. In LTL and AI specimen, a different type of damage takes place, namely the slippage between in-plane yarns (S-type) that leads to an extensive localised damage which directly results in the reduction of specimen's width.

The next step is to investigate whether the damage is homogenously distributed over the full gauge length of the specimen or not. So, three ROIs (top, centre, and bottom) of the specimen were scanned by X-ray, and "stitched" together as shown in Fig. 10. Three scans at different regions were carried out to maintain good image resolution. The horizontal lines seen in the X-ray images are the marking lines made to ensure correct transition for image stitching. Table 8 summarises the sequence of damage in the off-axis loaded specimens made by this X-ray analysis.

At $210 \mathrm{MPa}$ (95\% of UTS), as ORT specimen has smaller unit cell size (higher zbinder density) than LTL and AI, this enables stress redistribution over a longer span of the specimen, and prevents the slippage between in-plane yarns. Thus, the damage in ORT is seen to be uniformly distributed all over the gauge length of the specimen. On the contrary, both LTL and AI specimens exhibited localised damage due to S-type damage and extensive inter-yarn delamination. This is actually reflected in the global failure as shown in (Fig. 11). ORT specimens broke into two separate parts (Fig. 11a) with angled fracture where breakage of the z-binders is evident around the fracture area. Failure of LTL and AI specimens shown in Figs. 11b and c, respectively, occurred in localised region that is characterised by angled fracture. No apparent ply separation was found in LTL and AI specimen as the z-binder yarns prevented the separation between warp and weft layers. 
To further understand the underlying damage mechanisms, the failed specimens were X-ray scanned at different locations, i.e. close to the fracture region and away from it. After reconstructing the 3D scanned volumes, cross-sectional slices parallel to the binder plane "rotated 45o from the loading direction" are extracted (see Fig. 12). The three different locations are chosen in a systematic manner to show the damage in regions where there is no binder (Fig. 12a), with binder (Fig. 12b) and close to the fracture region (Fig. 12c). ORT scans show extensive transverse cracking homogenously distributed across the width of the specimen (Fig. 12a). In regions where the binding yarns exist (Fig. 12b), no inter-yarn delamination is observed as opposed to regions where there are no binding yarns (Fig. 12a). In addition, localised damage (Fig. 12b) occurs due to binder interlacing with weft/ warp yarns. Final failure happens when the binding yarns fracture (Fig. 12c) followed by extensive delamination. For LTL architecture, transverse cracking and delamination, between warp and weft layers (Fig. 12a), spans the whole width of the specimen. In regions with binding yarns, delamination is guided by their path (Fig. 12b). Close to the fracture region, the slippage (Fig. 12c) between planes and ply separations due to binders' breakage characterises the damage mechanism resulting into final failure. In case of AI architecture, multiple transverse cracking (Fig. 12a, b) is observed in the in-plane yarns "warp/ weft" with inter-yarn delamination (Fig. 12a-c). Localised induced damage (Fig. 12b) due to binder interlacement is clear in the form of matrix cracking. When binding yarns break, ply separation, between warp and weft planes, is observed (Fig. 12c) leading to final failure of the specimen.

\subsection{Effect of z-binder on energy absorption}

The energy absorbed per unit volume up to fracture (in $\mathrm{MJ} / \mathrm{m}^{3}$ ) is calculated as the area under the stress-strain curve. The energy absorption of 3D woven composites with different z-binder architectures is shown in Fig. 13. It is obvious that the specimens loaded in off-axis direction demonstrate greater energy absorption in comparison with their on-axis counterparts. More importantly, the z-binder architecture has a significant effect on the energy absorption of the off-axis loaded specimens. Under off-axis loading, ORT architecture absorbs energy almost three times higher than other 3D architectures. Furthermore, ORT specimens loaded in off-axis direction absorbs energy five times higher than that loaded in on-axis direction. This suggest the following: (i) based on energy 
absorption criterion, all 3D woven composites perform better under off-axis rather than onaxis loading; (ii) among all 3D woven composites investigated here, ORT performs the best in terms of energy absorption under off-axis loading. These findings can be used for the analysis of composite structures which may employ 3D woven composites for better response under multi-axial loading and impact resistance, where energy absorption is of prime interest.

When 3D woven composite are subjected to off-axis loading, the warp and weft yarns that are biased with certain angle tend to reorient towards the principal loading axis. During the reorientation process, the so-called "scissoring effect" takes place between the warp, weft and binder yarns. This reorientation process allows further strain to be borne by the composite laminate and consequently energy absorption. Table 9 shows the rotation angles of 3D woven composites measured experimentally 95\% UTS of the different specimens.

ORT specimens exhibit the largest rotation angle as compared to other specimens indicating that orthogonal z-binder coupled with small unit cells provides the best interlocking mechanism for in-plane yarns. The interlocking mechanism, with high fibre rotation angle at failure as exemplified by ORT 3D woven composites, improves their shear performance (failure strain, energy absorption) compared to other woven architectures.

\section{Concluding remarks}

Different architectures of 3D woven composites (orthogonal, ORT; layer-to-layer, LTL; angle interlock, AI) were characterised in terms of on-axis and off-axis mechanical properties and the influence of z-binder. Several remarks can be made from present investigation. The z-binder increases void content in $3 \mathrm{D}$ woven composites since the amount of resin flowing between warp and weft tows is partly inhibited by the binders; in this case, orthogonal architecture induces the highest amount of void in comparison to other architectures. Regardless of the weaving architecture type, the stiffness and tensile strength of 3D woven composites under on-axis loading mainly depends on the directional fibre volume fraction of warp and weft yarns. Among all textile architectures, 3D orthogonal woven composites exhibit the best performance (highest failure strength and failure strain) 
under off-axis loading due to interlocking mechanism provided by z-binder. This interlocking mechanism increases the rotation angle of warp and weft yarns, and thus the ability of the yarns to bear extensive off-axis strain. Moreover, as the ORT specimen has smaller unit cell size and higher z-binder density, this enables the stress redistribution over a longer span of the specimen, and prevents the slippage between in-plane yarns. So, the damage is uniformly distributed all over the gauge length of the specimen. The 3D orthogonal woven composites exhibit the highest energy absorption among other architectures during off-axis loading, which may pave the way for their use in composite structures designed with energy criterion as well as impact performance.

\section{Acknowledgments}

Authors would like to acknowledge the financial support from University of Manchester (UoM) and from Baseline Research Funds from King Abdullah University of Science and Technology (KAUST). We also acknowledge the technical support from the Northwest Composites Certification and Evaluation Facility (NCCEF). We would also like to thank Dr. Adam Joesbury from NCCEF for his helpful technical discussions.

\section{References}

[1] Stig F. 3D-woven Reinforcement in Composites. 2012.

[2] Hao A, Sun B, Qiu Y, Gu B. Dynamic properties of 3-D orthogonal woven composite T-beam under transverse impact. Compos Part A Appl Sci Manuf 2008;39:1073-82. doi:10.1016/j.compositesa.2008.04.012.

[3] Ji C, Sun B, Qiu Y, Gu B. Impact damage of 3D orthogonal woven composite circular plates. Appl Compos Mater 2007;14:343-62. doi:10.1007/s10443-008-9050$\mathrm{X}$.

[4] Luo Y, Lv L, Sun B, Qiu Y, Gu B. Transverse impact behavior and energy absorption of three-dimensional orthogonal hybrid woven composites. Compos Struct 2007;81:202-9. doi:10.1016/j.compstruct.2006.08.011.

[5] Seltzer R, González C, Muñoz R, LLorca J, Blanco-Varela T. X-ray microtomography analysis of the damage micromechanisms in 3D woven 
composites under low-velocity impact. Compos Part A Appl Sci Manuf 2013;45:49_ 60. doi:10.1016/j.compositesa.2012.09.017.

[6] Gerlach R, Siviour CR, Wiegand J, Petrinic N. In-plane and through-thickness properties, failure modes, damage and delamination in 3D woven carbon fibre composites subjected to impact loading. Compos Sci Technol 2012;72:397-411. doi:10.1016/j.compscitech.2011.11.032.

[7] L. Tong, A.P. Mouritz MB. Chapter 2 Manufacture of 3D Fibre Preforms. 3D Fibre Reinf. Polym. Compos., 2009.

[8] Stig F, Hallström S. Influence of crimp on 3D-woven fibre reinforced composites. Compos Struct 2013;95:114-22. doi:10.1016/j.compstruct.2012.07.022.

[9] Stig F, Hallström S. Assessment of the mechanical properties of a new 3D woven fibre composite material. Compos Sci Technol 2009;69:1686-92. doi:10.1016/j.compscitech.2008.04.047.

[10] L. Tong, A.P. Mouritz MB. Chapter 5 3D Woven Composites. 3D Fibre Reinf. Polym. Compos., 2009.

[11] Dai S, Cunningham PR, Marshall S, Silva C. Influence of fibre architecture on the tensile, compressive and flexural behaviour of 3D woven composites. Compos Part A Appl Sci Manuf 2015;69:195-207. doi:10.1016/j.compositesa.2014.11.012.

[12] Ansar M, Xinwei W, Chouwei Z. Modeling strategies of 3D woven composites: A review. Compos Struct 2011;93:1947-63. doi:10.1016/j.compstruct.2011.03.010.

[13] Behera BK, Dash BP. Mechanical behavior of 3D woven composites. Mater Des 2015;67:261-71. doi:10.1016/j.matdes.2014.11.020.

[14] Cox BN, Dadkhah MS, Morris WL, Flintoff JG. Failure mechanisms of 3D woven composites in tension, compression, and bending. Acta Metall Mater 1994;42:396784. doi:10.1016/0956-7151(94)90174-0.

[15] Cox BN, Dadkhah MS, Morris WL. On the tensile failure of 3D woven composites. Compos Part A Appl Sci Manuf 1996;27:447-58. doi:10.1016/1359$835 X(95) 00053-5$. 
[16] Lomov S V, Bogdanovich a E, Karahan M, Mungalov D, Verpoest I, Leuven KU. Mechanical Behaviour of Non-Crimp 3D Woven Carbon / Epoxy Composite Under in-Plane Tensile Loading. ICCM 18, 2011, p. 1-5.

[17] Leong KH, Lee B, Herszberg I, Bannister MK. Effect of binder path on the tensile properties and failure of multilayer woven CFRP composites. Compos Sci Technol 2000;60:149-56. doi:10.1016/S0266-3538(99)00108-6.

[18] Quinn JP, McIlhagger a. T, McIlhagger R. Examination of the failure of 3D woven composites. Compos Part A Appl Sci Manuf 2008;39:273-83. doi:10.1016/j.compositesa.2007.10.012.

[19] Pochiraju K. Three-Dimensionally Woven and Braided Composites. II: An Experimental Characterization. Polym Compos 1999;20:733-47.

[20] Tan P, Tong L, Steven GP, Ishikawa T. Behavior of 3D orthogonal woven CFRP composites. Part I. Experimental investigation. Compos Part A Appl Sci Manuf 2000;31:259-71. doi:10.1016/S1359-835X(99)00070-6.

[21] Warren KC, Lopez-Anido R a., Goering J. Experimental investigation of threedimensional woven composites. Compos Part A Appl Sci Manuf 2015;73:242-59. doi:10.1016/j.compositesa.2015.03.011.

[22] Visrolia a., Meo M. Multiscale damage modelling of 3D weave composite by asymptotic homogenisation. Compos Struct 2013;95:105-13. doi:10.1016/j.compstruct.2012.07.018.

[23] Vallons K, Duque I, Lomov SV, Verpoest I. Loading direction dependence of the tensile stiffness, strength and fatigue life of biaxial carbon/epoxy NCF composites. Compos Part A Appl Sci Manuf 2011;42:16-21. doi:10.1016/j.compositesa.2010.09.009.

[24] Ivanov DS, Lomov S V., Bogdanovich AE, Karahan M, Verpoest I. A comparative study of tensile properties of non-crimp 3D orthogonal weave and multi-layer plain weave E-glass composites. Part 2: Comprehensive experimental results. Compos Part A Appl Sci Manuf 2009;40:1144-57. doi:10.1016/j.compositesa.2009.04.032.

[25] Yudhanto A, Lubineau G, Ventura IA, Watanabe N, Iwahori Y, Hoshi H. Damage 
characteristics in 3D stitched composites with various stitch parameters under inplane tension. Compos Part A Appl Sci Manuf 2015;71:17-31.

doi:10.1016/j.compositesa.2014.12.012.

[26] Jia X, Xia Z, Gu B. Micro/meso-scale damage analysis of three-dimensional orthogonal woven composites based on sub-repeating unit cells. J Strain Anal Eng Des 2012;47:313-28. doi:10.1177/0309324712444671.

[27] Daggumati S, Van Paepegem W, Degrieck J, Praet T, Verhegghe B, Xu J, et al. Local strain in a 5-harness satin weave composite under static tension: Part II Meso-FE analysis. Compos Sci Technol 2011;71:1217-24. doi:10.1016/j.compscitech.2011.03.020.

[28] Obert E, Daghia F, Ladevèze P, Ballere L. Micro and meso modeling of woven composites: Transverse cracking kinetics and homogenization. Compos Struct 2014;117:212-21. doi:10.1016/j.compstruct.2014.06.035.

[29] Blaysat B, Florentin E, Lubineau G, Moussawi A. A Dissipation Gap Method for full-field measurment-based identification of elasto-plastic material parameters. Proc 2011 Am Control Conf 2011:1885-91. doi:10.1002/nme.

[30] Fuller JD, Wisnom MR. Pseudo-ductility and damage Suppression in thin ply angleply carbon-epoxy laminates. Compos Part A Appl Sci Manuf 2013;69:64-71. doi:10.1016/j.compositesa.2014.11.004.

[31] Yu B, Bradley RS, Soutis C, Hogg PJ, Withers PJ. 2D and 3D imaging of fatigue failure mechanisms of 3D woven composites. Compos Part A Appl Sci Manuf 2015. doi:10.1016/j.compositesa.2015.06.013.

[32] Bogdanovich AE, Karahan M, Lomov S V., Verpoest I. Quasi-static tensile behavior and damage of carbon/epoxy composite reinforced with 3D non-crimp orthogonal woven fabric. Mech Mater 2013;62:14-31. doi:10.1016/j.mechmat.2013.03.005.

[33] Mittelstedt C, Becker W. Free-Edge Effects in Composite Laminates. Appl Mech Rev 2007;60:217. doi:10.1115/1.2777169.

[34] Mittelstedt C, Becker W. Interlaminar Stress Concentrations in Layered Structures: Part I - A Selective Literature Survey on the Free-Edge Effect since 1967. J Compos 
Mater 2004;38:1037-62. doi:10.1177/0021998304040566.

[35] Sun CT, Zhou SG. Failure of Quasi-Isotropic Composite Laminates with Free Edges. J Reinf Plast Compos 1988;7:515-57. doi:10.1177/073168448800700602. 


\section{$\underline{\text { List of Figures }}$}

Figure 1. Schematics of 3D woven composites: (a) ORT, (b) LTL, (c) AI

Figure 2. Cutting orientation to produce 3D woven composite specimens in warp, weft and bias (off-axis) directions

Figure 3. X-CT scans: (a, c, e) unit cell reconstruction and (b, d, f) cross-section view along the binder path for ORT, LTL, AI respectively

Figure 4. (a) Experimental setup for tensile test, (b) typical randomly distributed speckle pattern used for DIC

Figure 5. On-axis stress-strain curves: (a) ORT, (b) LTL, (c) AI

Figure 6. Strain contour ( $\left.\varepsilon_{y y}\right)$ obtained by DIC system and unit cell representation in (a) ORT, (b) LTL, (c) AI specimens (note: black frames show the respective unit cell)

Figure 7. Off-axis stress-strain curves: (a) ORT, (b) LTL, (c) AI

Figure 8. On-axis failure mode in (a) ORT, (b) LTL, (c) AI

Figure 9. (a) Stress levels (Points A, B, C, D) in the off-axis stress-strain curve selected for damage observation by X-ray, (b) X-ray images of ORT, LTL, AI specimens at specified points

Figure 10. Stitched X-ray scans for the interrupted test

Figure 11. Off-axis failure mode in (a) ORT, (b) LTL, (c) AI

Figure 12. Off-axis X-ray cross-sectional slices in planes (a) without binder, (b) with binder, (c) close to the fracture region

Figure 13. Energy absorption of 3D woven composites 


\section{List of Tables}

Table 1. Specification of textile architecture of 3D woven composites

Table 2. Volume fraction of constituents (fibre, matrix, void) in 3D woven composites

Table 3. Directional fibre volume fraction in 3D woven composites

Table 4. Young's modulus, tensile strength and failure strain of 3D composites in warp and weft directions

Table 5. Off-axis tensile modulus, strength and failure strain of 3D woven composites

Table 6. Strain and stress levels at the "knee point" for off-axis tensile test

Table 7. Nomenclature of damage types

Table 8. Sequence of damage events during tensile loading of off-axis 3D woven composites

Table 9. Experimental rotation angles for off-axis specimens at $95 \%$ UTS 
Table 1. Specification of textile architecture of 3D woven composites

\begin{tabular}{cccc}
\hline Parameter & ORT & LTL & AI \\
\hline Warp fibre count & $12 \mathrm{k}$ & $12 \mathrm{k}$ & $12 \mathrm{k}$ \\
Weft fibre count & $12 \mathrm{k}$ & $12 \mathrm{k}$ & $12 \mathrm{k}$ \\
z-binder fibre count & $6 \mathrm{k}$ & $12 \mathrm{k}$ & $6 \mathrm{k}$ \\
Ends/cm (warp) & 31.52 & 17.73 & 31.52 \\
Picks/cm (weft) & 38 & 36 & 34 \\
Binders/cm (z-binder) & 3.94 & 17.73 & 3.94 \\
Areal density $\left(\mathrm{g} / \mathrm{m}^{2}\right)$ & 3353 & 3260 & 3044 \\
\hline
\end{tabular}

Table 2. Volume fraction of constituents (fibre, matrix, void) in 3D woven composites

\begin{tabular}{lccc}
\hline \multirow{2}{*}{ Constituent } & \multicolumn{3}{c}{ 3D composite } \\
\cline { 2 - 4 } & ORT & LTL & AI \\
\hline Fibre (\%) & $51.35 \pm 0.45$ & $59.16 \pm 0.24$ & $55.4 \pm 0.80$ \\
Matrix (\%) & $46.02 \pm 0.43$ & $39.21 \pm 0.14$ & $42.18 \pm 0.97$ \\
Voids (\%) & $2.63 \pm 0.02$ & $1.63 \pm 0.13$ & $2.42 \pm 0.19$ \\
\hline
\end{tabular}

Table 3. Directional fibre volume fraction in 3D woven composites

\begin{tabular}{lccc}
\hline Direction of fibre tow & ORT & LTL & AI \\
\hline Warp (\%) & 21.57 & 14.36 & 25.58 \\
Weft (\%) & 26.00 & 29.15 & 27.59 \\
z-binder (\%) & 3.77 & 15.65 & 2.22 \\
\hline
\end{tabular}

Table 4. Young's modulus, tensile strength and failure strain of 3D composites in warp and weft directions

\begin{tabular}{|c|c|c|c|c|c|c|}
\hline \multirow{2}{*}{$\begin{array}{c}\text { Textile } \\
\text { architecture }\end{array}$} & \multicolumn{2}{|c|}{ Young's modulus (GPa) } & \multicolumn{2}{|c|}{ Tensile strength (MPa) } & \multicolumn{2}{|c|}{ Failure strain $(\%)$} \\
\hline & $\begin{array}{c}\text { Warp } \\
\left(0^{\circ}\right) \\
\end{array}$ & $\begin{array}{l}\text { Weft } \\
\left(90^{\circ}\right) \\
\end{array}$ & $\begin{array}{l}\text { Warp } \\
\left(0^{\circ}\right) \\
\end{array}$ & $\begin{array}{l}\text { Weft } \\
\left(90^{\circ}\right) \\
\end{array}$ & $\begin{array}{c}\text { Warp } \\
\left(0^{\circ}\right) \\
\end{array}$ & $\begin{array}{l}\text { Weft } \\
\left(90^{\circ}\right) \\
\end{array}$ \\
\hline ORT & $56.6 \pm 0.39$ & $70.0 \pm 1.86$ & $711 \pm 17.39$ & $862 \pm 23.07$ & $1.20 \pm 0.02$ & $1.25 \pm 0.03$ \\
\hline LTL & $53.9 \pm 0.46$ & $76.6 \pm 0.84$ & $681 \pm 21.82$ & $1029 \pm 29.82$ & $1.37 \pm 0.04$ & $1.34 \pm 0.05$ \\
\hline AI & $71.0 \pm 1.92$ & $69.9 \pm 1.42$ & $913 \pm 40.26$ & $924 \pm 31.68$ & $1.28 \pm 0.08$ & $1.28 \pm 0.09$ \\
\hline
\end{tabular}


Table 5. Off-axis tensile modulus, strength and failure strain of 3D woven composites

\begin{tabular}{cccc}
\hline Textile architecture & Tensile Modulus $(\mathrm{GPa})$ & Tensile strength $(\mathrm{MPa})$ & Failure strain $(\%)$ \\
\hline ORT & $7.93 \pm 0.25$ & $226.33 \pm 11.04$ & $24.20 \pm 1.22$ \\
LTL & $9.93 \pm 0.37$ & $132.02 \pm 3.71$ & $11.27 \pm 0.33$ \\
AI & $8.82 \pm 0.28$ & $172.76 \pm 0.55$ & $13.29 \pm 0.48$ \\
\hline
\end{tabular}

Table 6 Strain and stress levels at the "knee point" for off-axis tensile test

\begin{tabular}{ccc}
\hline Textile architecture & Axial strain $(\%)$ & Tensile stress $(\mathrm{MPa})$ \\
\hline ORT & $1.84 \pm 0.19$ & $88.91 \pm 2.80$ \\
LTL & $1.45 \pm 0.03$ & $90.88 \pm 2.58$ \\
AI & $1.71 \pm 0.16$ & $94.70 \pm 0.86$ \\
\hline
\end{tabular}

Table 7. Nomenclature of damage types

\begin{tabular}{cl}
\hline Code & Damage type \\
\hline $\mathbf{F}$ & Free edge matrix crack between yarns \\
$\mathbf{Z}$ & Z-binder induced damage \\
$\mathbf{T}$ & Transverse crack within yarns \\
$\mathbf{D}$ & Inter-yarn matrix delamination \\
$\mathbf{S}$ & Slippage between in-plane tows "warp/weft" \\
\hline
\end{tabular}

Table 8. Sequence of damage events during tensile loading of off-axis 3D woven composites

\begin{tabular}{ccccc}
\hline Point & Applied stress (MPa) & ORT & LTL & AI \\
\hline A & 0 & -- & -- & -- \\
B & 60 & F & F & F \\
C & 110 & F,T,Z & F,T,D & F,T,Z \\
D & $95 \%$ UTS $(210,120,170)$ & F,T,D,Z & F,T,D,S & F,T,D ,Z,S \\
\hline
\end{tabular}

Table 9. Experimental rotation angles for off-axis specimens at $95 \%$ UTS

\begin{tabular}{cccc}
\hline Parameter & ORT & LTL & AI \\
\hline Exp. Rotation angle $(\mathrm{deg})$ & $12.07 \pm 0.12$ & $7.93 \pm 0.49$ & $5.43 \pm 0.73$ \\
\hline
\end{tabular}


(a)

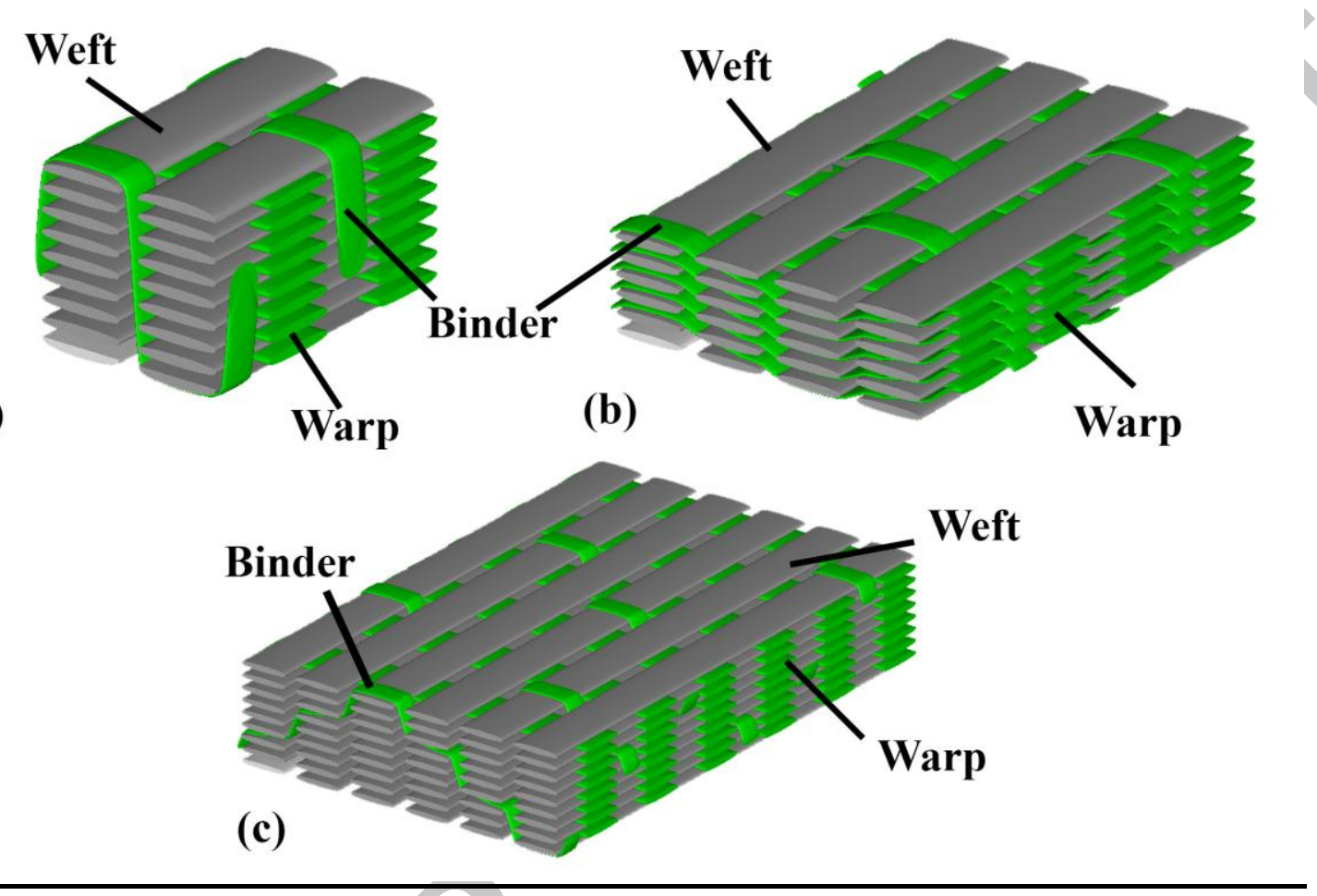




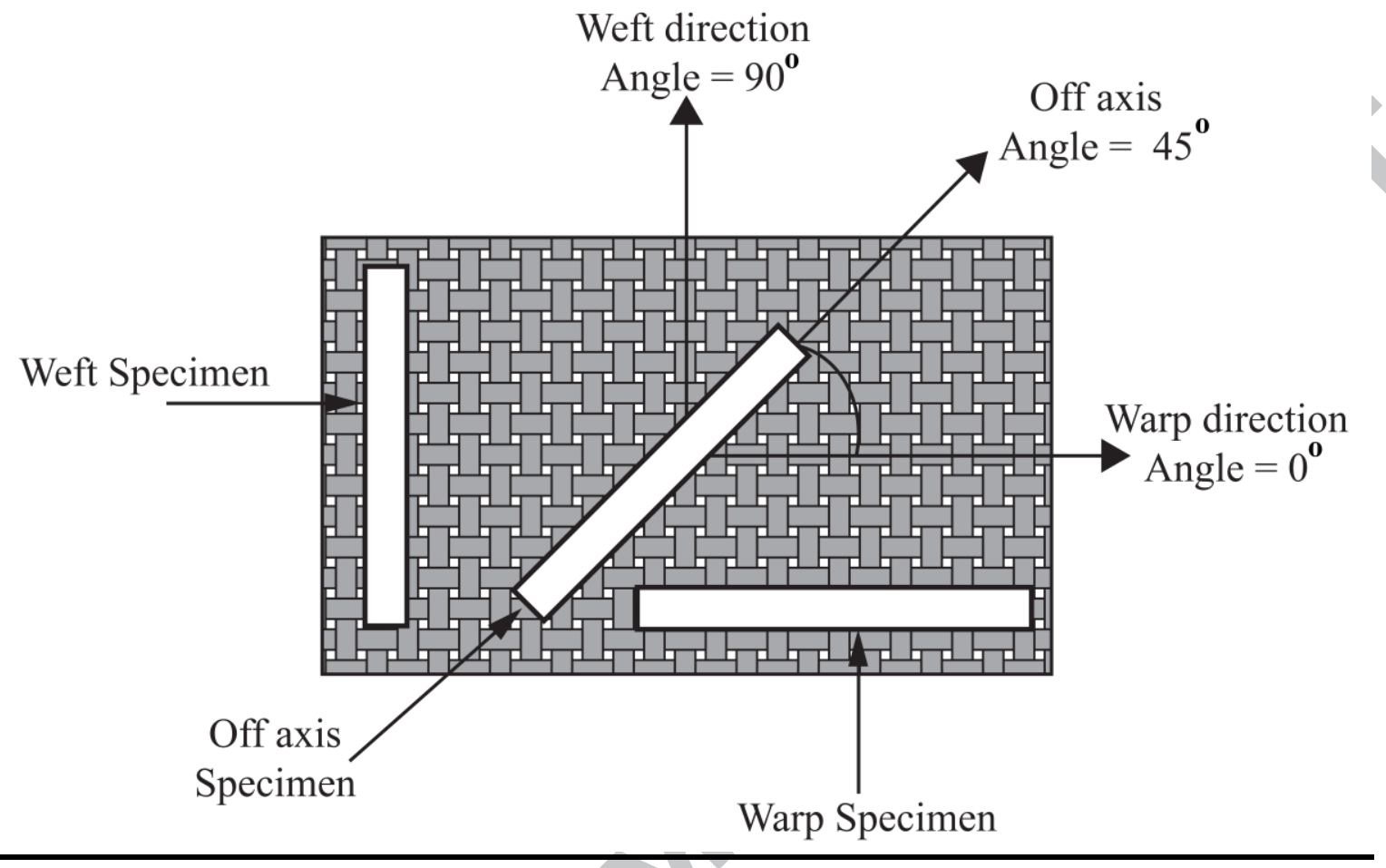




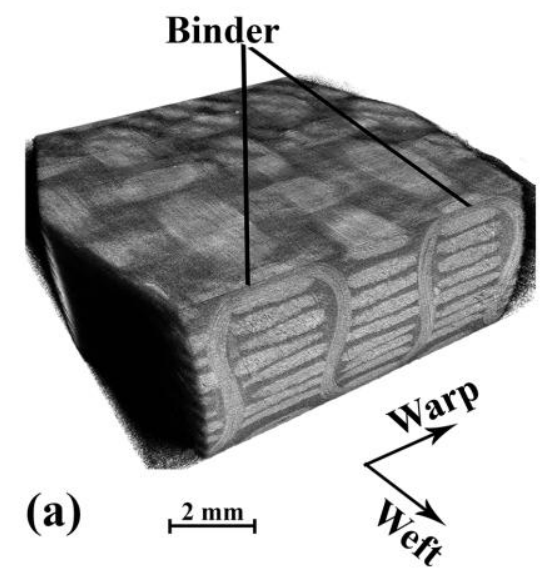

Binder

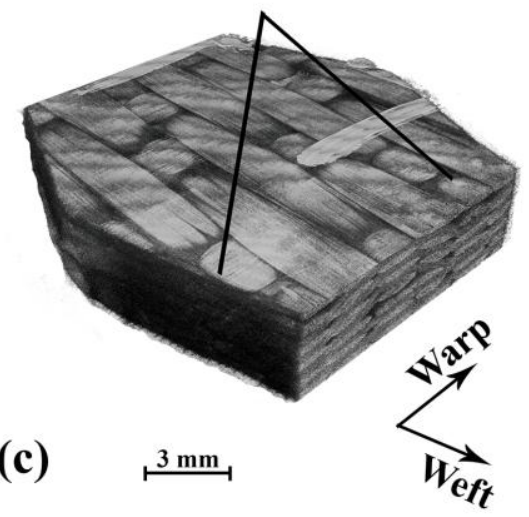

(c) $\quad 3 \mathrm{~mm}$

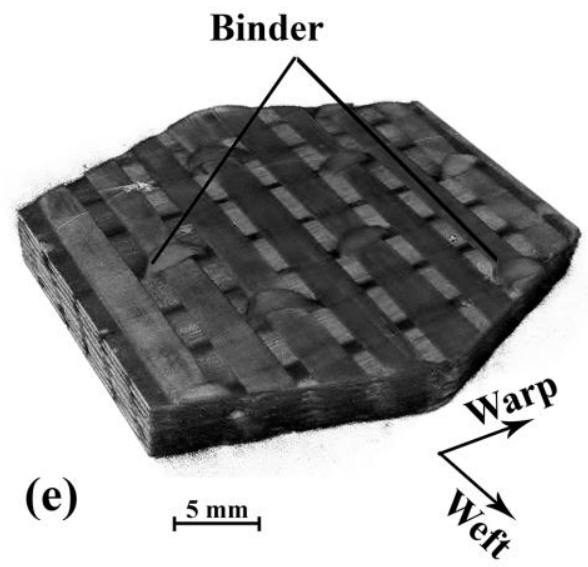

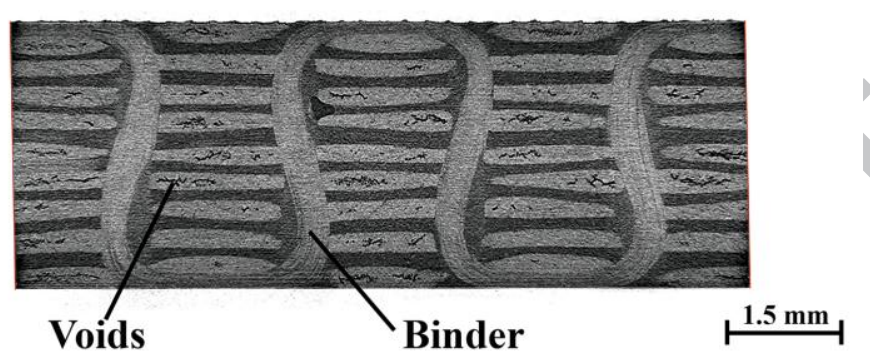

(b)

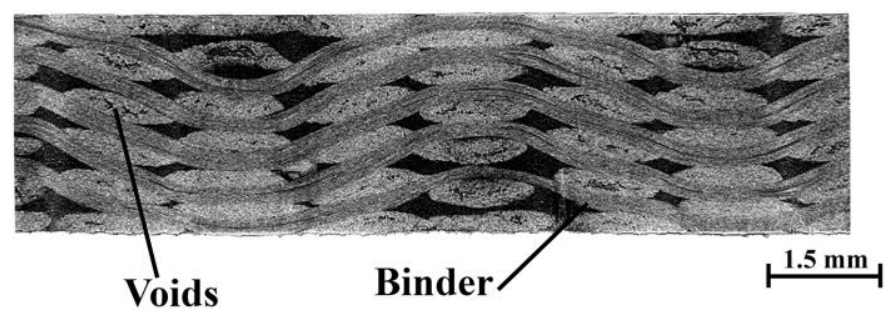

(d)

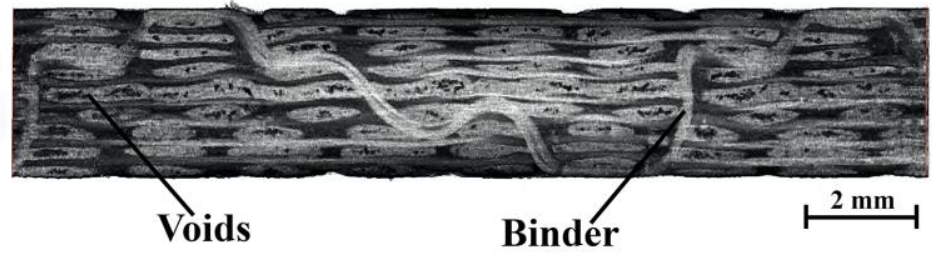

(f) 


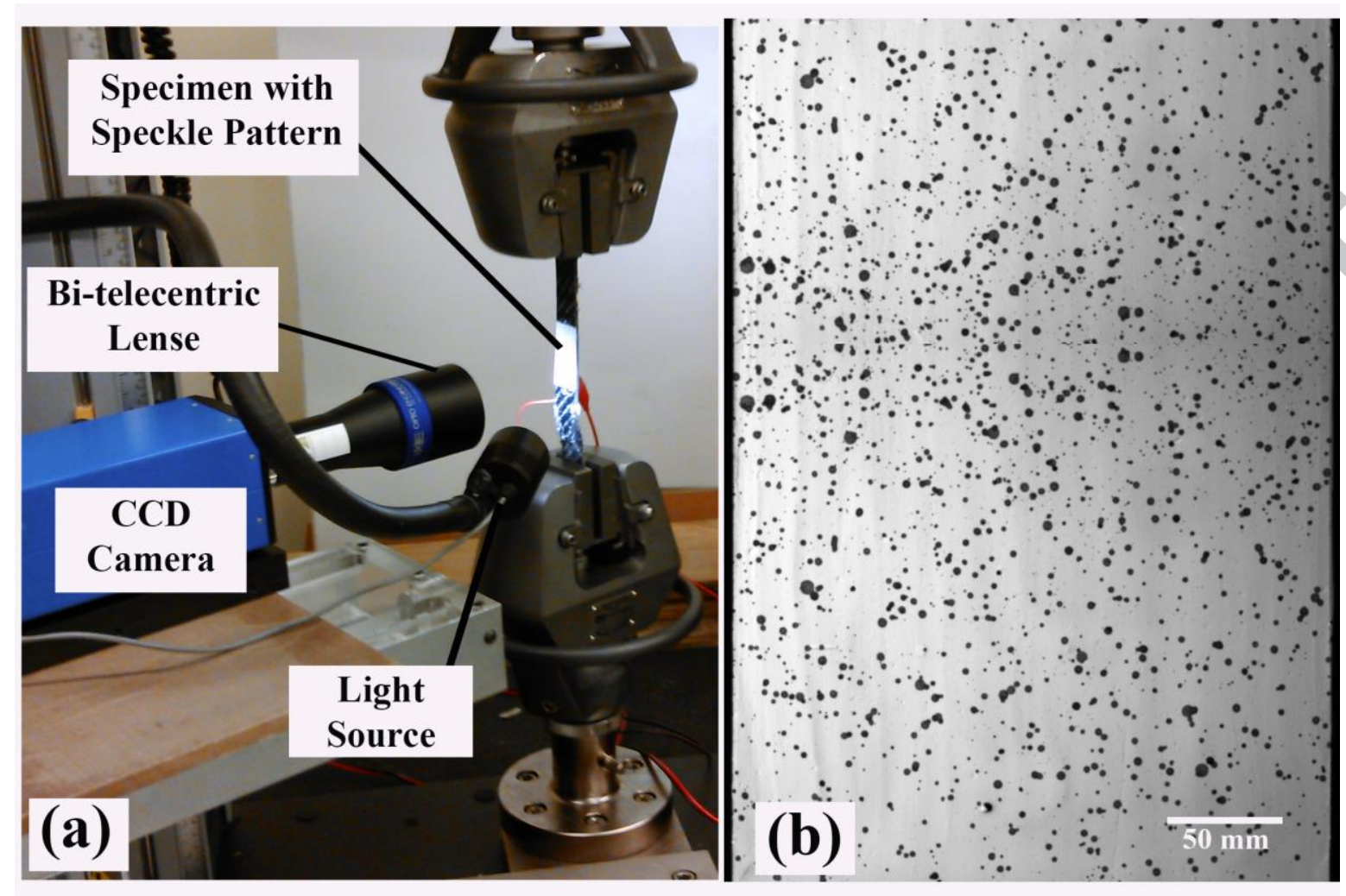



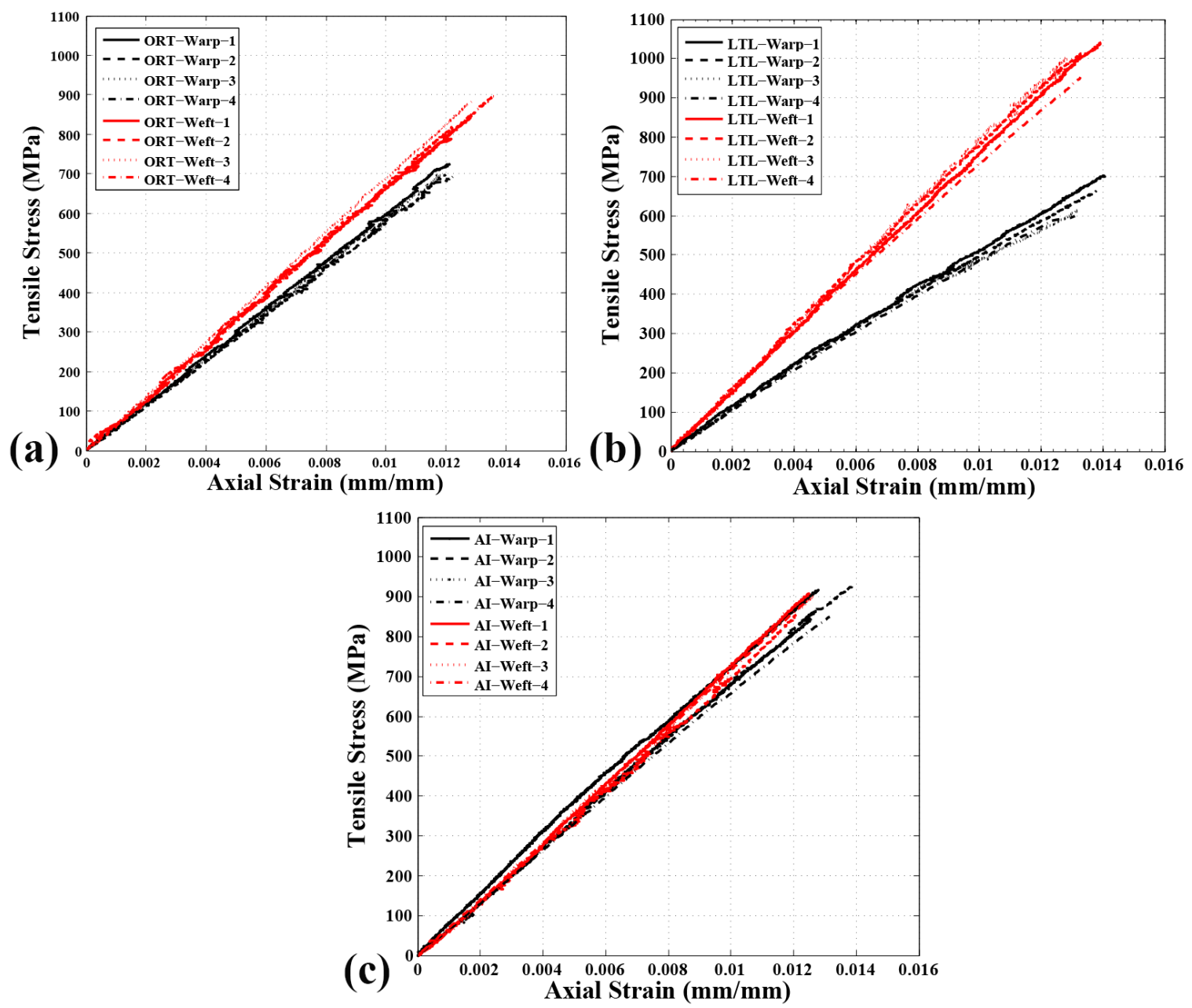


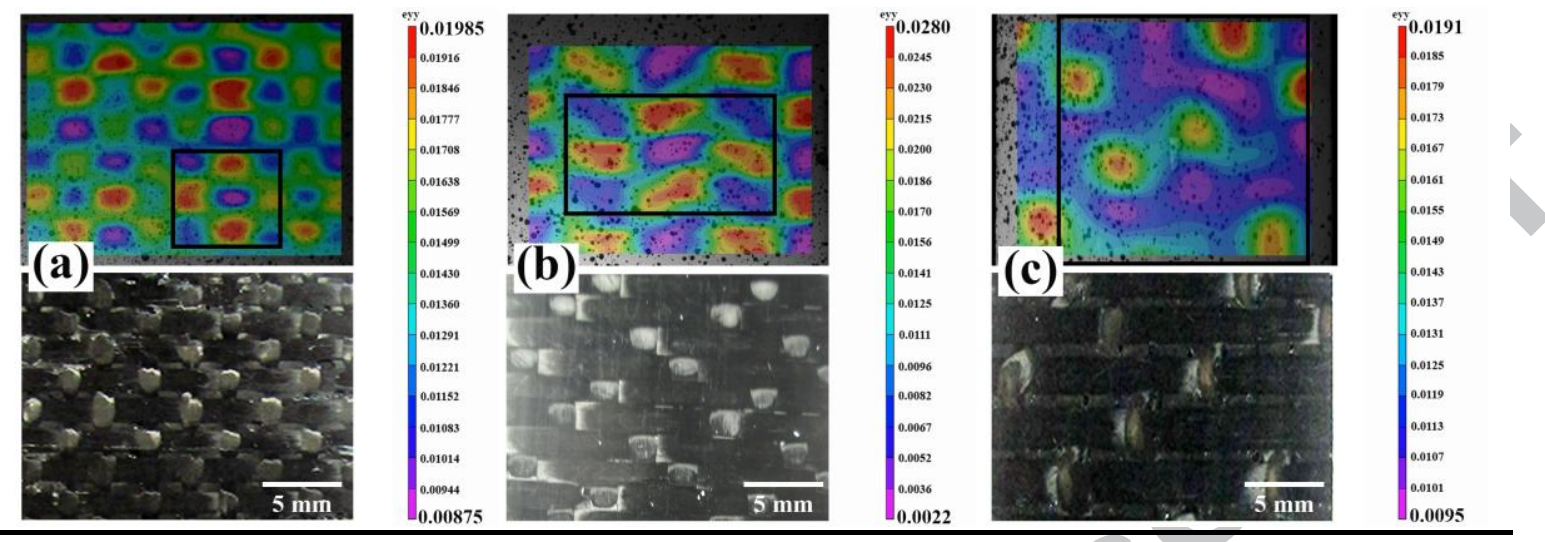



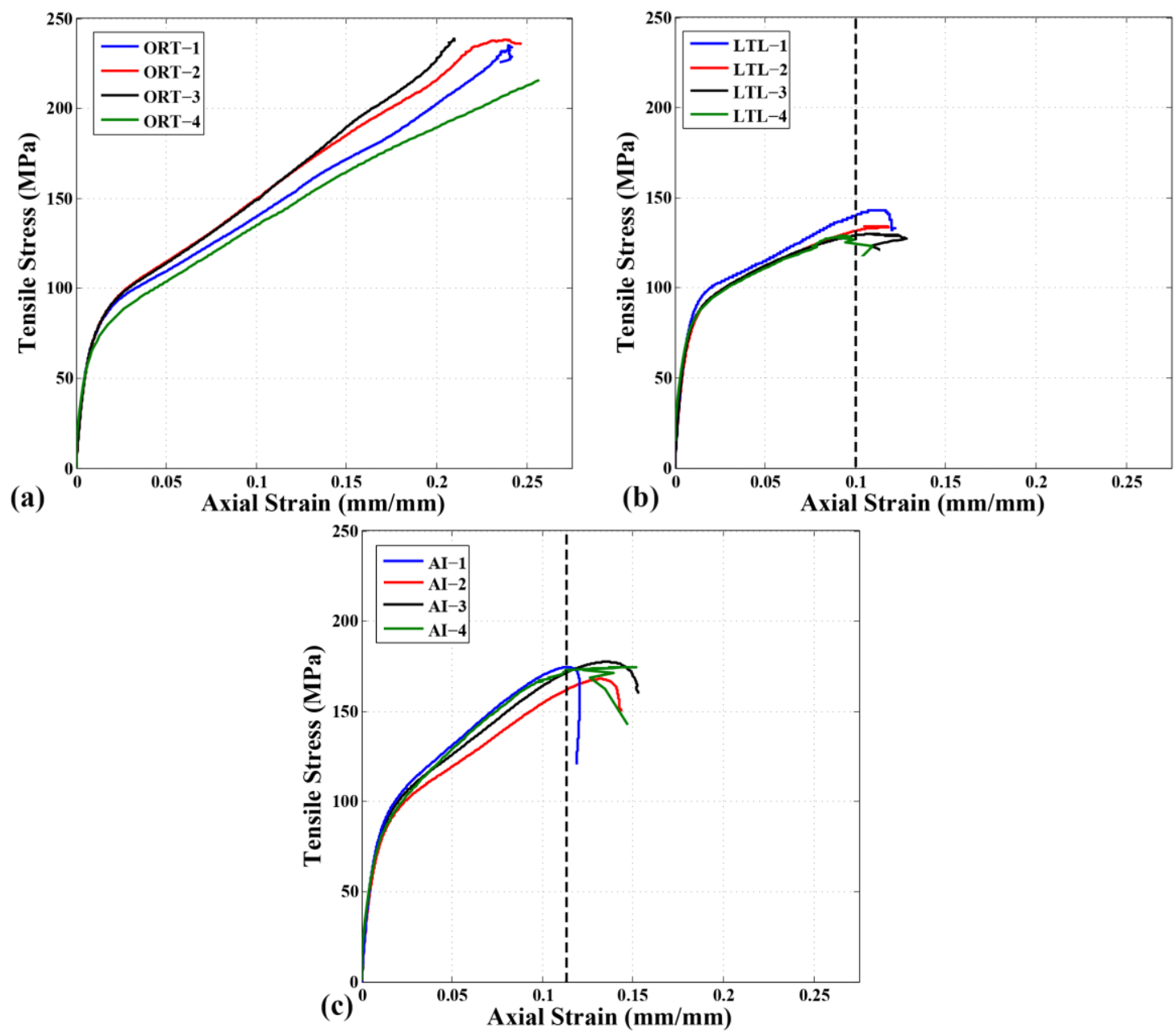

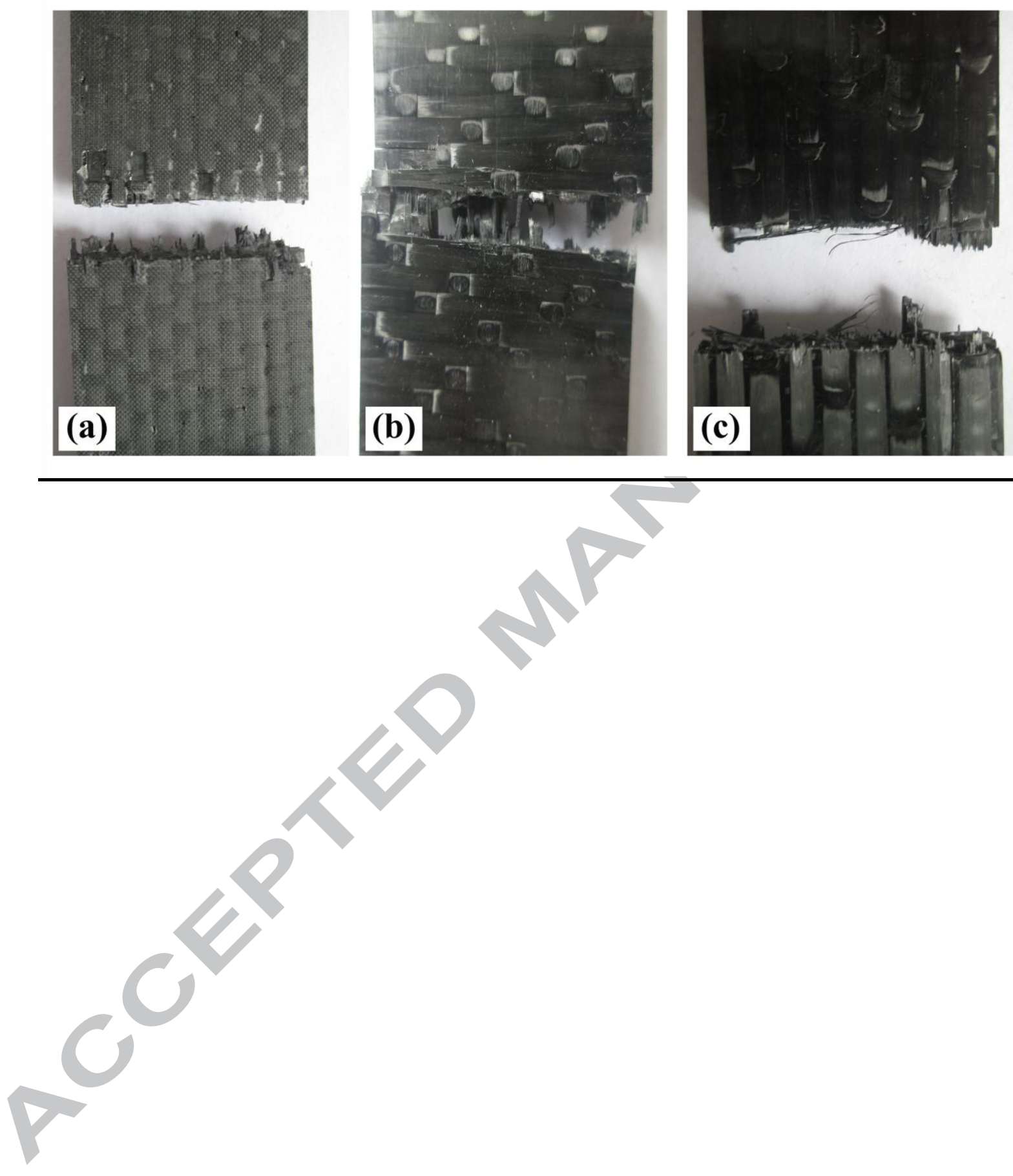


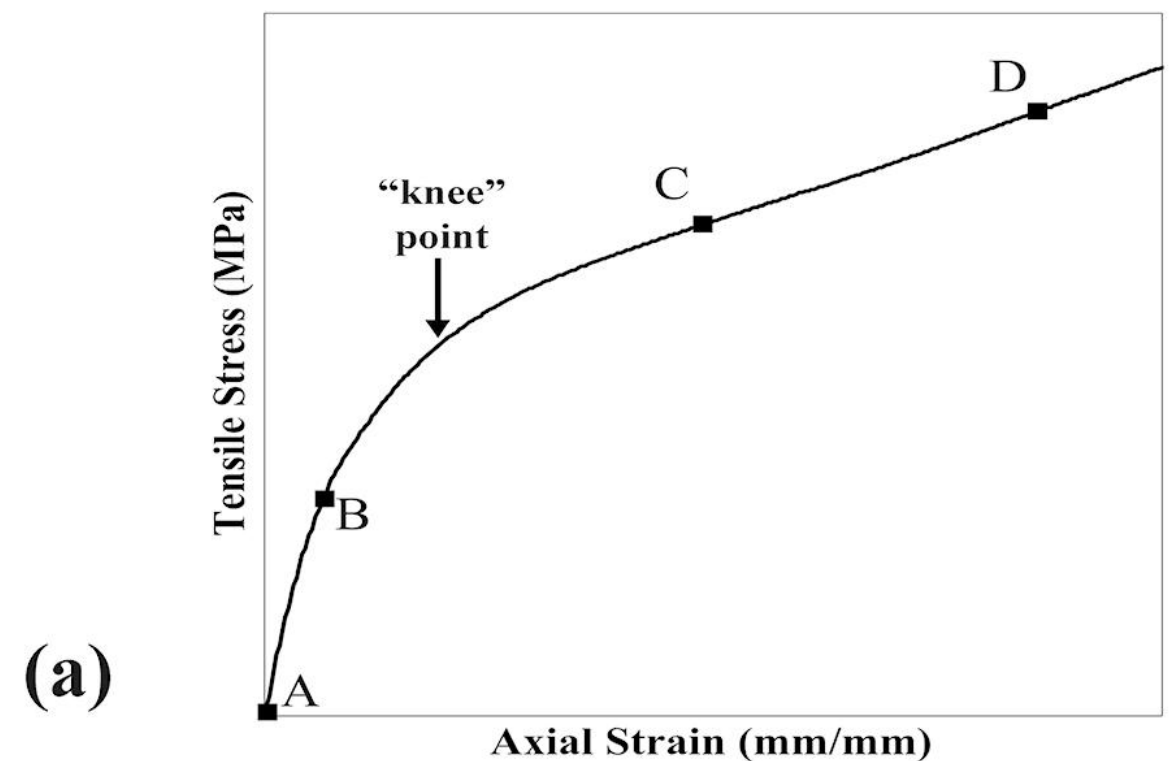

(A)

(B)

(C)

(D)

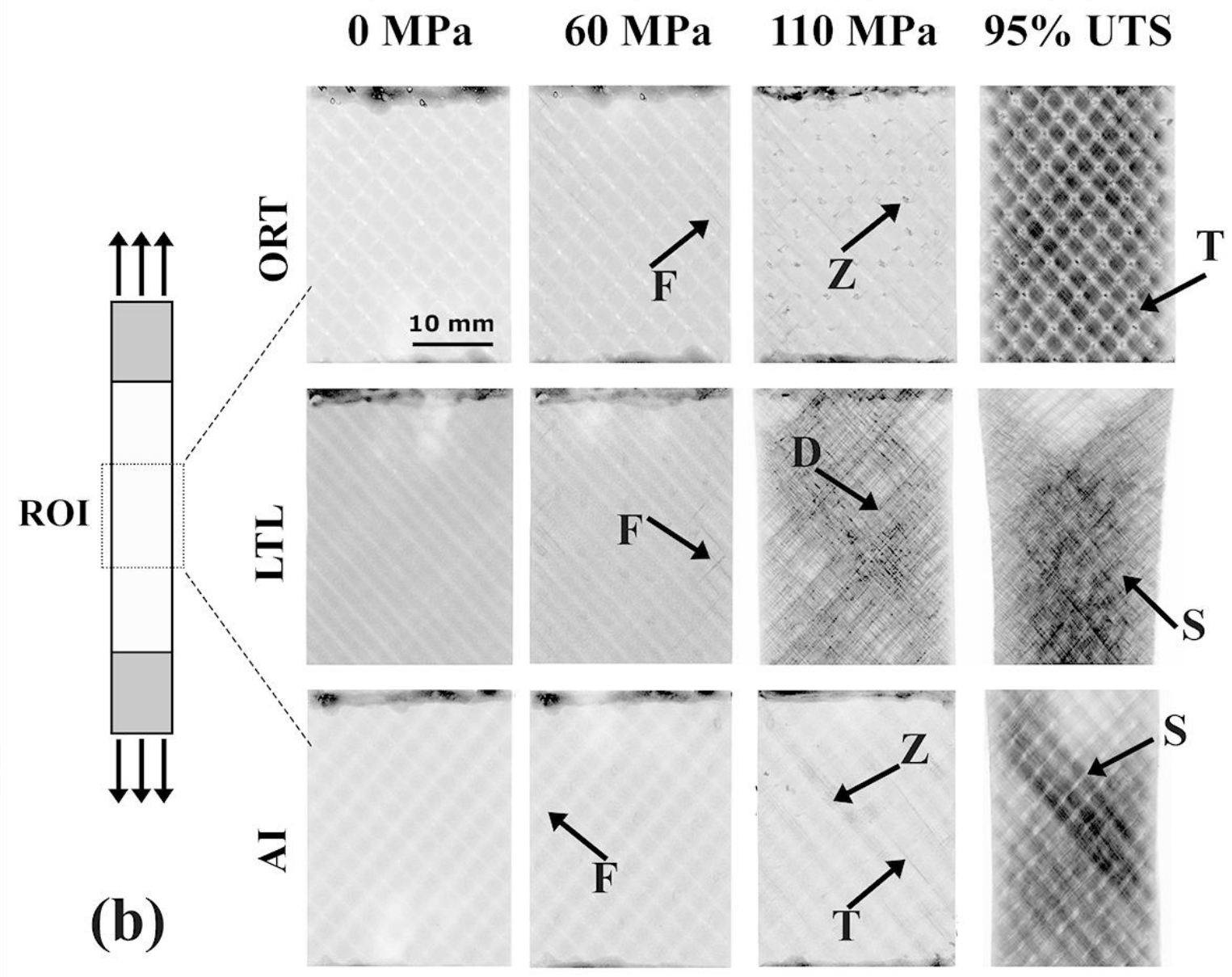



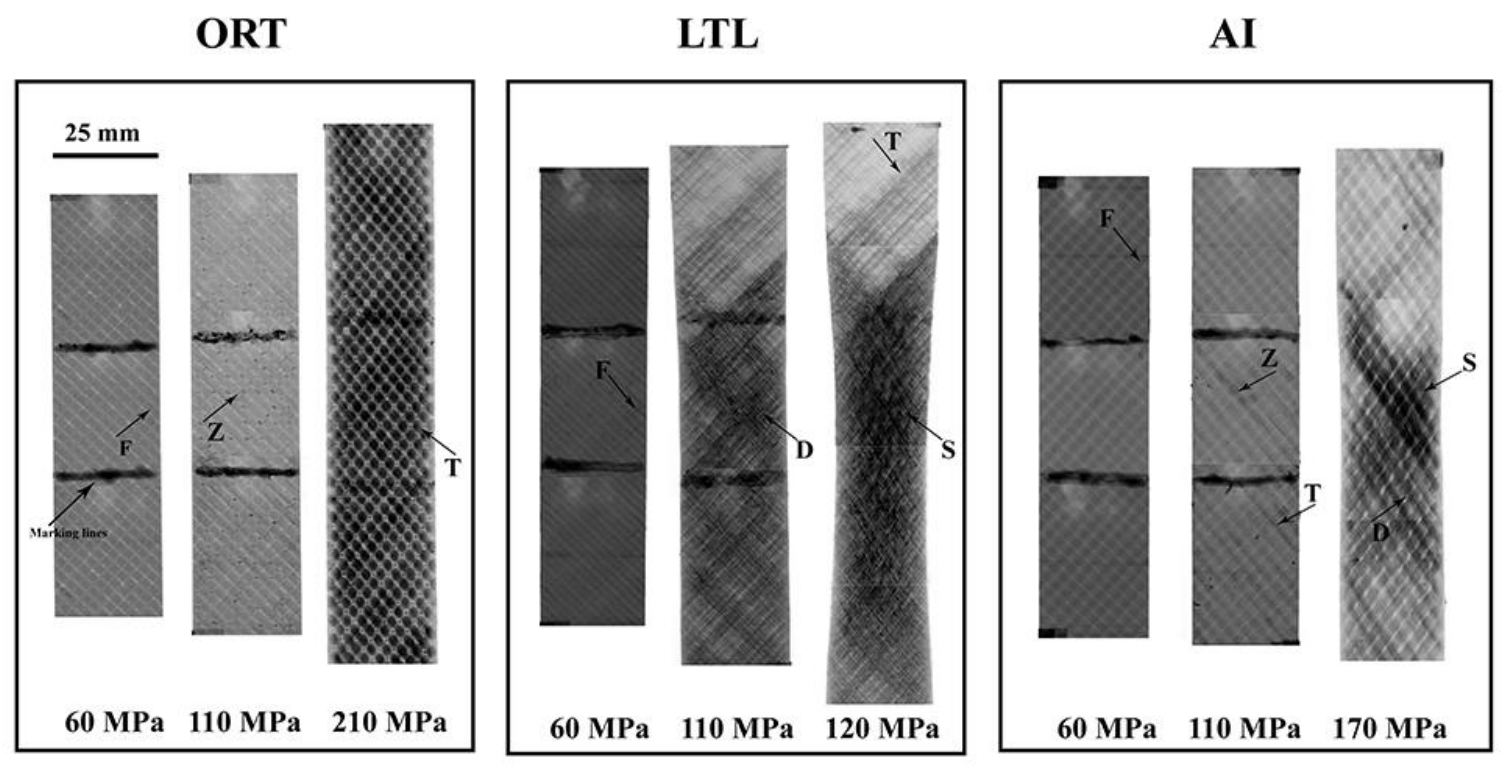

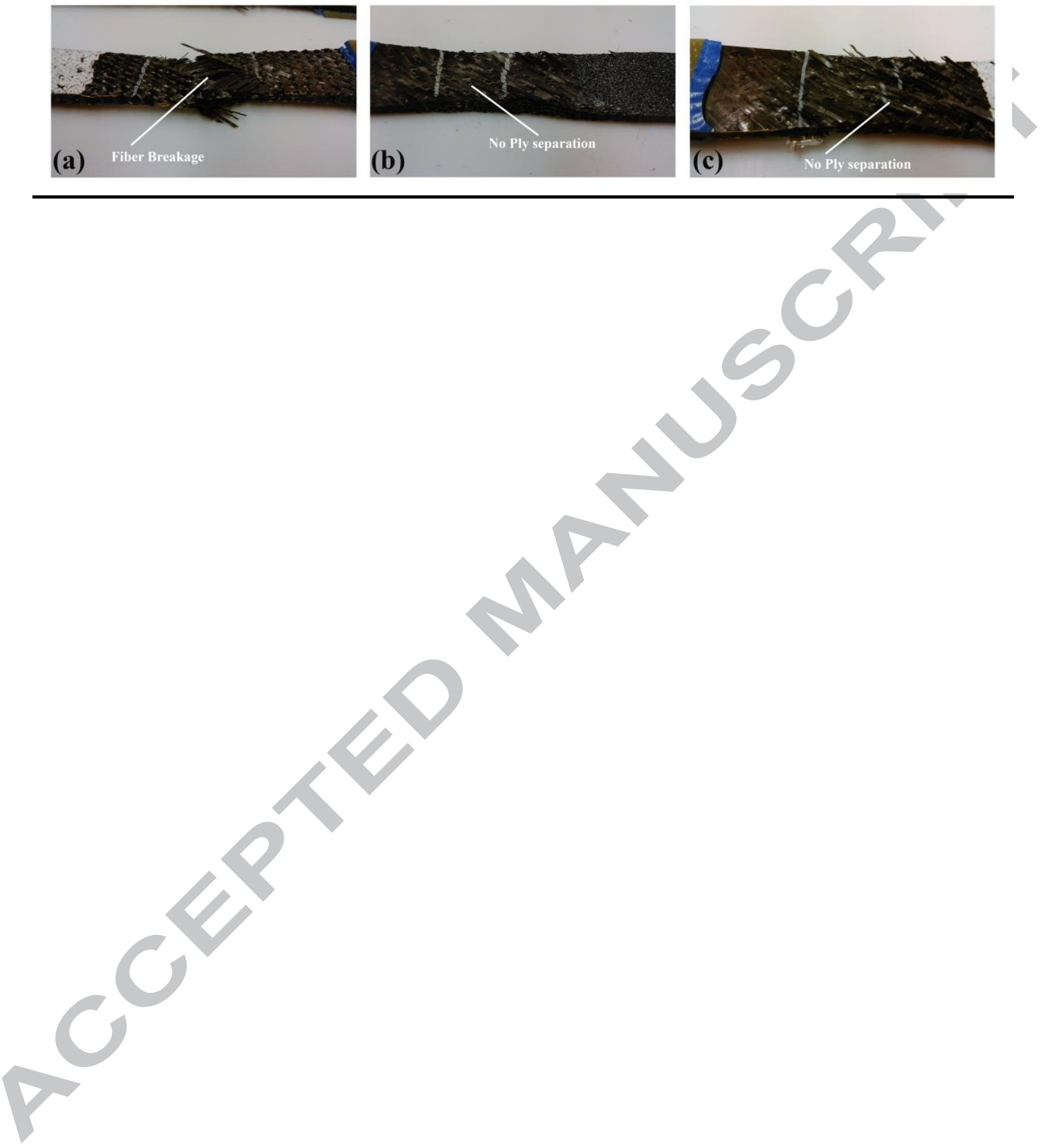

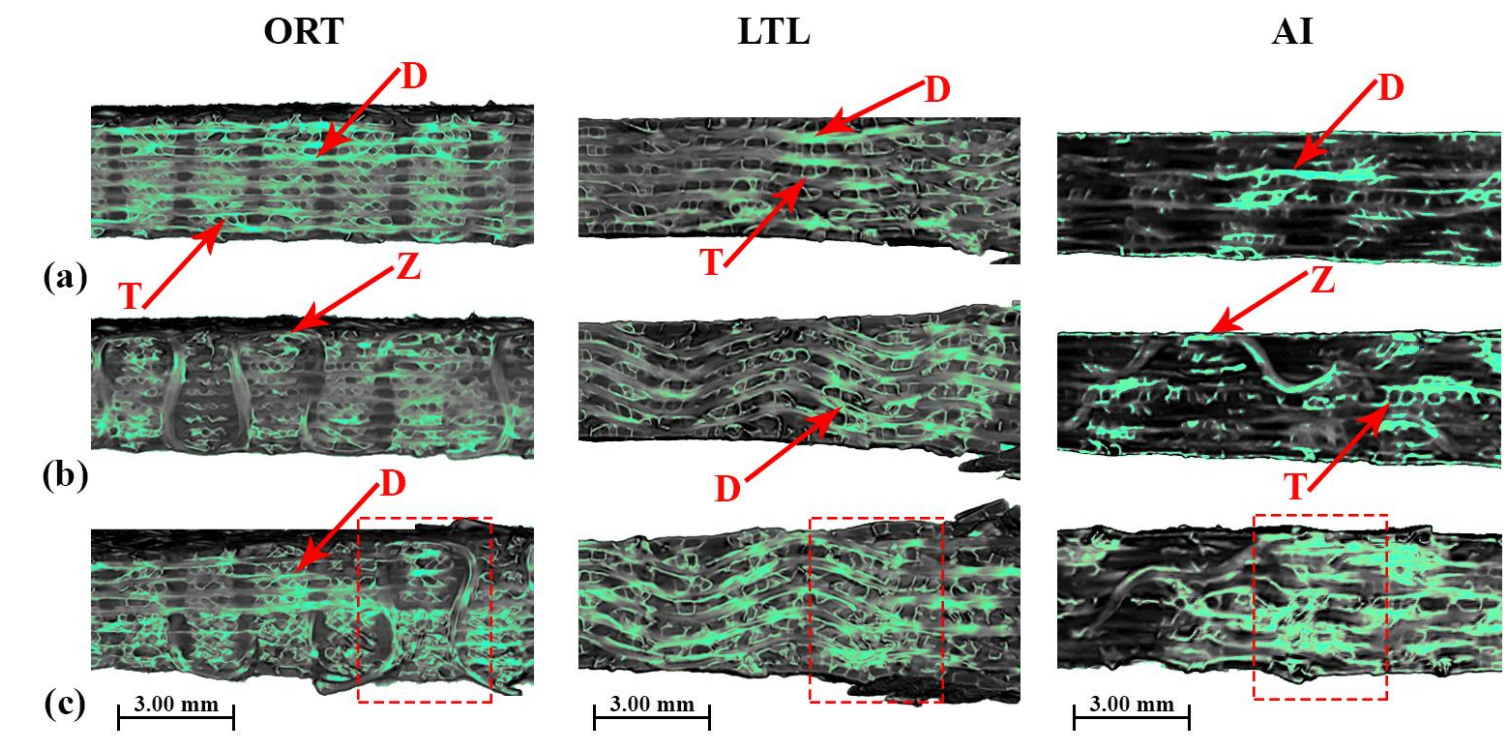


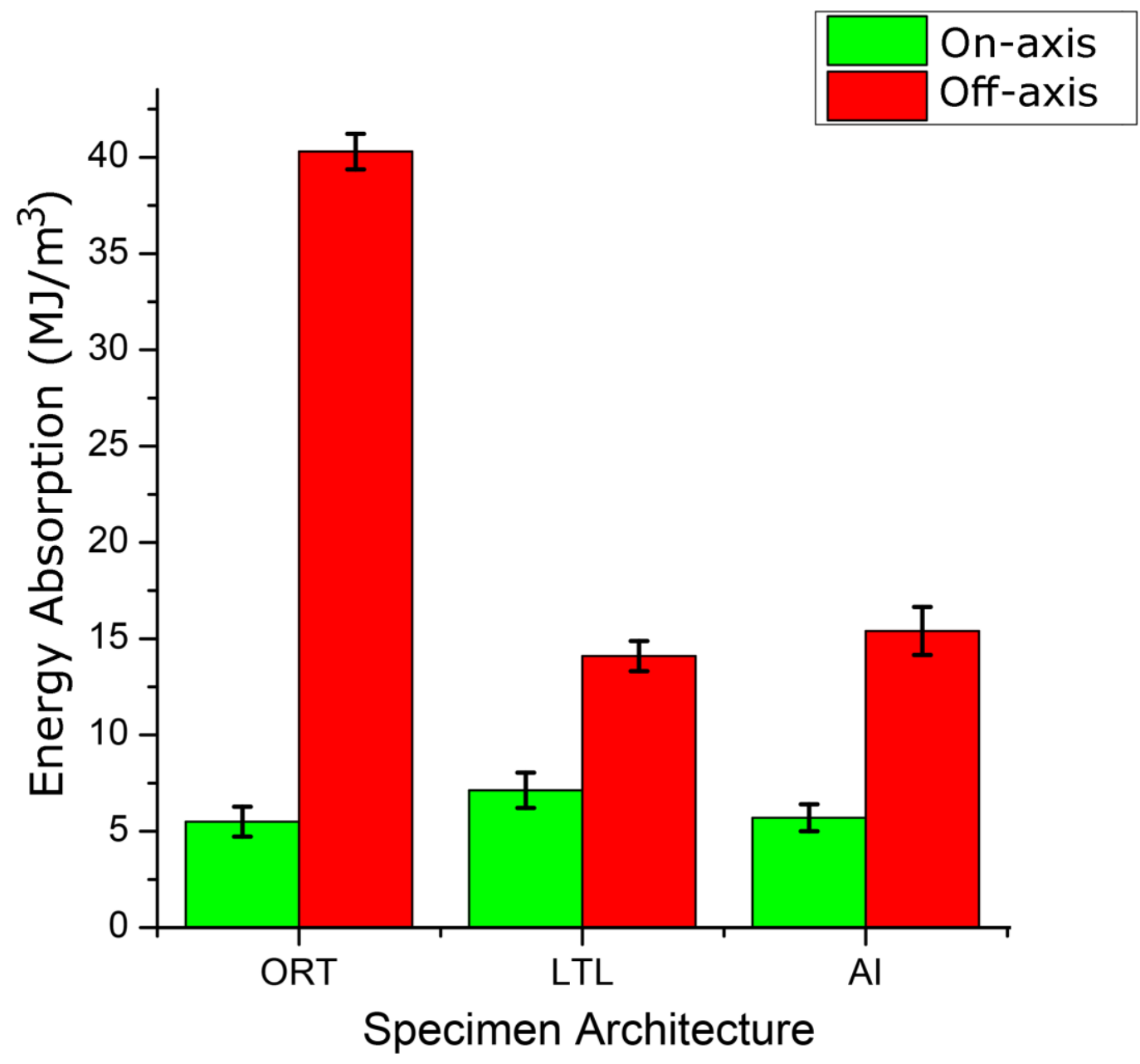

